\title{
Putative Polycomb Group Protein ASXL2
}

National Cancer Institute

\section{Source}

National Cancer Institute. Putative Polycomb Group Protein ASXL2. NCI Thesaurus. Code C116298.

Putative Polycomb group protein ASXL2 (1435 aa, 154 kDa) is encoded by the human ASXL2 gene. This protein plays a role in both the activation of transcription and chromatin remodeling. 